Check for updates

Cite this: RSC Adv., 2017, 7, 30610

Received 22nd April 2017

Accepted 31st May 2017

DOI: $10.1039 / \mathrm{c} 7 \mathrm{ra04531j}$

rsc.li/rsc-advances

\title{
Phenothiazin-N-yl-capped 1,4-diketo-3,6- diphenylpyrrolo[3,4-c]pyrrole exhibiting strong two-photon absorption and aggregation-enhanced one- and two-photon excitation red fluorescence $\dagger$
}

\author{
Kai Zhang, Zhongwei Liu, Shian Ying, Mingshuai Chen, Shanfeng Xue, \\ Haichang Zhang* and Wenjun Yang (D)*
}

\begin{abstract}
Water-soluble or water-dispersible two-photon dyes with strong fluorescence and large two-photon absorption (2PA) cross sections are very desirable for nano- and bio-photonics, but are still scarce. Herein, a new 1,4-diketo-3,6-diphenylpyrrolo[3,4-c]pyrrole derivative end-capped with two phenothiazin$N$-yl donors (PDPP) is synthesized and its one- and two-photon optical properties are investigated in both solution and aqueous dispersions. The results show that PDPP exhibits solvent-independent one-photon solution absorption and emission properties with low fluorescence quantum yields, but strong red fluorescence in both aqueous dispersion and the crystalline state. This aggregation-enhanced emission (AEE) effect enables PDPP to have not only large 2PA cross sections but also a remarkably enhanced twophoton fluorescence action cross section in aqueous dispersions. Thus, 2PA-active PDPP is a promising candidate for two-photon science and technology.
\end{abstract}

\section{Introduction}

Conjugated organic molecules derived from common pigments and dyes have been attracting much attention due to their ease of synthesis, accessibility and modification, and subtle manipulation of their molecular chemical structure could result in promising applications in the organic optical and optoelectronic fields. 1,4-Diketo-pyrrolo[3,4-c]pyrrole derivatives (DPPs) represent a class of brilliant red high-performance pigments which have exceptional light, weather and heat stability, and high light fastness. ${ }^{1}$ Commercial DPP pigments are almost insoluble or limitedly soluble in common organic solvents, which could be well solved by introducing alkyl chains on the lactam unit to eliminate strong intermolecular hydrogen bond interactions. Thus, some soluble mono- and bis-alkylated DPPs with high fluorescence efficiency in common organic solvents have been obtained. ${ }^{2}$ In the past two decades, DPP derivatives have been used as building blocks to construct promising conjugated small molecules and polymers applicable in fieldeffect transistors and photovoltaic devices, etc. ${ }^{2 c, 3,4}$ In recent years, our group and others have found that donor-capped DPP derivatives are excellent two-photon fluorescent dyes with high

Key Laboratory of Rubber-Plastics of Ministry of Education, Shandong Provincial Key Laboratory of Rubber-Plastics, School of Polymer Science \& Engineering, Qingdao University of Science \& Technology, 53-Zhengzhou Road, Qingdao, 266042, P. R. China.E-mail: ywjph2004@qust.edu.cn; haichangzhang@hotmail.com

$\dagger$ Electronic supplementary information (ESI) available. See DOI: 10.1039/c7ra04531j light and heat stability, and mono-alkylated DPPs could be used as one- and two-photon fluorescence sensors for fluoride anions since their two-photon fluorescence responses are effective and distinct. $^{2 a, 2 b, 5}$ It is known that water-soluble or water-dispersible organic fluorescent dyes with large two-photon absorption (2PA) cross sections $(\delta)$ are of great utility for nano- and bio-photonics, but are still limited. ${ }^{2 a, 6}$ Moreover, it has been considered that large $\delta_{\max }$ and molecular weight ratios (such as $\delta_{\max } / \mathrm{MW}>1.0$ ) are more valuable for applications that require strong $2 \mathrm{PA}$, such as optical limiting and 3-D micro-fabrication, or strong twophoton excitation fluorescence (2PEF), such as bio-imaging. ${ }^{7}$ Therefore, it is still necessary to further develop such stably water-dispersible two-photon fluorescent dyes.

To obtain strong fluorescence in aqueous media, bulky moieties with aggregation-induced emission activity have to be introduced into the DPP core periphery. ${ }^{8}$ However, successful examples are rather limited. Moreover, in most cases, the fluorescence quenching effect still appears in aqueous media with a high water content. Although our group and others have found recently that 3,6-diaryl conjugation bridges and endcapped groups could significantly affect the aggregation and stimuli-responsive behaviours of DPP-based derivatives, ${ }^{9}$ herein, we attempt to combine efficient two-photon absorption with aggregation-enhanced emission by designing a new small size DPP-based 2PA dye (PDPP, Scheme 1) in a form suitable to produce stable aqueous aggregate dispersions. PDPP is characterized by a quasi-symmetric D-A-D quadrupolar motif with a rotatable phenyl as the conjugation-bridge and vibratile 

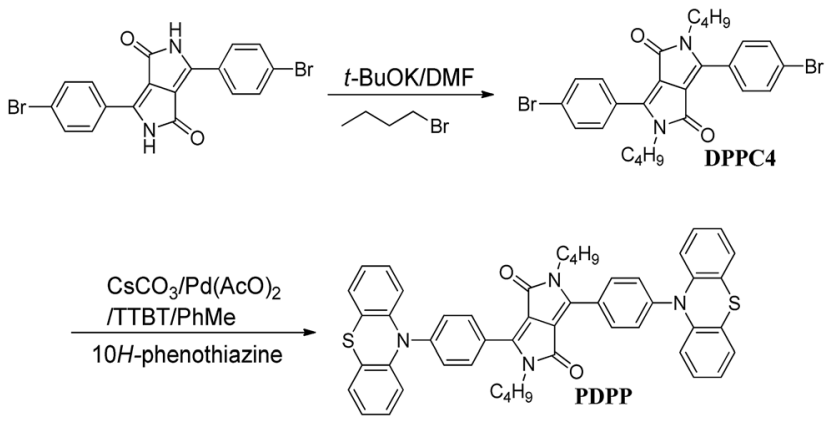

Scheme 1 Synthetic route and chemical structure of the target material PDPP.

butterfly-like phenothiazin- $N$-yl as the end-groups. We report that PDPP could form stable red-emitting aqueous dispersions without the presence of an emulsifier and it exhibits large 2PA cross sections and remarkably aggregation-enhanced one- and two-photon excitation red fluorescence.

\section{Experimental}

\section{General information}

Materials. 3,6-Bis(4-bromophenyl)pyrrolo[3,4-c]pyrrole$1,4(2 H, 5 H)$-dione was from our previous work. ${ }^{9 a}$ Toluene (PhMe) over metallic sodium and $N, N$-dimethylformamide (DMF) over calcium hydride were distilled before use. 10H-Phenothiazine, palladium acetate, tri(t-butyl)phosphine (TTBP), potassium tertbutoxide $\left(t\right.$-BuOK), 1-bromobutane $\left(\mathrm{C}_{4} \mathrm{H}_{9} \mathrm{Br}\right)$, and cesium carbonate $\left(\mathrm{Cs}_{2} \mathrm{CO}_{3}\right)$ were obtained from Energy Chemical Ltd. Shanghai, China and used without further purification. The other solvents were of analytical grade and obtained commercially.

Measurements. ${ }^{1} \mathrm{H}(500 \mathrm{MHz})$ and ${ }^{13} \mathrm{C}$ NMR $(125 \mathrm{MHz})$ spectra were recorded using a Bruker-AC500 spectrometer in $\mathrm{CDCl}_{3}$ at $298 \mathrm{~K}$ and tetramethylsilane (TMS) as the internal standard. UV-visible absorption and fluorescence emission spectra were recorded on Hitachi U-4100 and Hitachi F-4600 spectrophotometers, respectively. Differential scanning calorimetry (DSC) curves were determined on a Netzsch DSC (204F1) instrument at a heating (or cooling) rate of $10{ }^{\circ} \mathrm{C} \mathrm{min}^{-1}$. Thermogravimetric analysis (TGA) was performed on a Netzsch (209F1) thermo-gravimetric analyzer under a nitrogen atmosphere $\left(50 \mathrm{~mL} \mathrm{~min}{ }^{-1}\right)$ at a heating rate of $10{ }^{\circ} \mathrm{C} \mathrm{min}^{-1}$.

The solution fluorescence quantum yield $(\Phi)$ was determined via a dilute solution method using Rhodamine $\mathrm{B}$ in methanol as the reference (r). ${ }^{10} \Phi_{\mathrm{s}}$ was calculated according to the equation: $\Phi_{\mathrm{s}}=\Phi_{\mathrm{r}}\left[A_{\mathrm{s}} / A_{\mathrm{r}}\right]\left[F_{\mathrm{r}} / F_{\mathrm{s}}\right]\left[n_{\mathrm{s}} / n_{\mathrm{r}}\right]^{2}$, ${ }^{11}$ where $\mathrm{r}$ and $\mathrm{s}$ represent the reference and sample, respectively, $\Phi$ is the solution fluorescence quantum yield, $A$ is the absorbance, $F$ is the emission area, and $n$ is the refractive index. The solid-state fluorescence efficiency was measured on a fluorescence integral sphere.

The molar extinction coefficients $(\varepsilon)$ were determined using a Hitachi U-4100 UV-visible spectrophotometer and calculated from the absorbance values of dilute solutions using the BeerLambert law $A=\varepsilon c L,{ }^{\mathbf{1 2}}$ where $A$ is the absorbance at a given wavelength, $c$ is the molar concentration of the samples and $L$ (cm) is the optical path length.

Two-photon absorption cross section $(\delta)$ was determined using a femtosecond Ti:sapphire oscillator (Avesta TiF-100M) with output laser pulses and average power of $100 \mathrm{~mW}$ as the excitation source. The laser pulses had a pulse duration of $80 \mathrm{fs}$ and repetition rate of $84.5 \mathrm{MHz}$ in the wavelength range of 710$1000 \mathrm{~nm}$. The pumping wavelengths were determined on a monochromator-CCD system. Rhodamine B in methanol was used as the reference (r). ${ }^{13}$ The two-photon absorption cross section $(\delta)$ of the sample $(\mathrm{s})$ was calculated at each wavelength according to the equation: $\delta_{\mathrm{s}}=\left[I_{\mathrm{s}} \Phi_{\mathrm{r}} n_{\mathrm{r}}{ }^{2} c_{\mathrm{r}}\right] /\left[I_{\mathrm{r}} \Phi_{\mathrm{s}} n_{\mathrm{s}}{ }^{2} c_{\mathrm{s}}\right] \delta_{\mathrm{r}},{ }^{14}$ where, $I$ is the integral area of the two-photon excitation fluorescence; $\Phi$ is the fluorescence quantum yield (assuming that $\Phi$ is unchanged under both one- and two-photon excitation), $n$ is the refractive index, and $c$ is the number density of the molecules in solution. The solution concentration for both sample and reference was $1.0 \times 10^{-5} \mathrm{M}$.

The ground-state geometry was optimized at the level of B3LYP/6-31G(d,p), and spatial distributions of the HOMO and LUMO of the compound were obtained from the optimized ground state structure.

\section{Synthesis}

2,5-Dibutyl-3,6-bis(4-bromophenyl)pyrrolo[3,4-c]pyrrole-1,4dione (DPPC4). 3,6-Bis(4-bromophenyl)pyrrolo[3,4-c]pyrrole1,4(2H,5H)-dione $(1.14 \mathrm{~g}, 2.56 \mathrm{mmol})$ and $t$-BuOK $(0.83 \mathrm{~g}, 7.40$ $\mathrm{mmol}$ ) in $30 \mathrm{~mL}$ anhydrous DMF were stirred for $1 \mathrm{~h}$ at $120{ }^{\circ} \mathrm{C}$ under a nitrogen atmosphere. Then 1-bromobutane $(1.75 \mathrm{~g}$, $12.80 \mathrm{mmol}$, in $5 \mathrm{~mL} \mathrm{DMF}$ ) was slowly added to the flask. The reaction was left for $24 \mathrm{~h}$ at $130{ }^{\circ} \mathrm{C}$. After cooling to room temperature, the mixture was poured into water and extracted with $\mathrm{CH}_{2} \mathrm{Cl}_{2}$. The organic phase was dried over anhydrous $\mathrm{MgSO}_{4}$ and the product was separated via silica column chromatography using $\mathrm{CH}_{2} \mathrm{Cl}_{2}$ as the eluent. A red solid was obtained (0.65 g, yield: $45 \%) .{ }^{1} \mathrm{H}$ NMR (500 $\left.\mathrm{MHz}, \mathrm{CDCl}_{3}, \mathrm{ppm}\right)$ : $\delta$ 7.76-7.61 (m, 8H), $3.74(\mathrm{t}, 4 \mathrm{H}, J=7.7 \mathrm{~Hz}), 1.52(\mathrm{~m}, 4 \mathrm{H}), 1.26$ $(\mathrm{m}, 4 \mathrm{H}, J=7.5 \mathrm{~Hz}), 0.85(\mathrm{t}, 6 \mathrm{H}, J=7.3 \mathrm{~Hz})$.

2,5-Dibutyl-3,6-(10-phenothiazinylphen)pyrrolo[3,4-c] pyrrole-1,4-dione (PDPP). Under a nitrogen atmosphere, DPPC4 (0.94 g, $1.68 \mathrm{mmol}), 10 H$-phenothiazine (1.68 g, $8.43 \mathrm{~mol}$ ), $\mathrm{Cs}_{2} \mathrm{CO}_{3}(1.21 \mathrm{~g}, 3.71 \mathrm{mmol})$, palladium acetate ${ }^{15}(3.8 \mathrm{mg}, 1.68$ $\mu \mathrm{mol})$, TTBP $(7.3 \mathrm{mg}, 2.52 \mu \mathrm{mol})$ and toluene $(20 \mathrm{~mL})$ were added to a $50 \mathrm{~mL}$ one-neck flask. The mixture was refluxed for $24 \mathrm{~h}$ and then extracted with $\mathrm{CH}_{2} \mathrm{Cl}_{2}(3 \times 50 \mathrm{~mL})$. The organic phase was dried over $\mathrm{MgSO}_{4}$ and the solvent was removed via rotary evaporation. The crude product was purified by silica column chromatography using petroleum ether $/ \mathrm{CH}_{2} \mathrm{Cl}_{2}(1 / 2, \mathrm{v} /$ $\mathrm{v})$ as the eluent to afford the target compound $(0.28 \mathrm{~g}$, yield: 21\%). ${ }^{1} \mathrm{H}$ NMR (500 MHz, $\left.\mathrm{CDCl}_{3}, \mathrm{ppm}\right): \delta 7.88$ (d, 4H, $J=8.5$ $\mathrm{Hz})$, 7.41-7.27 (d, 8H), $7.17(\mathrm{t}, 4 \mathrm{H}, J=7.8,1.5 \mathrm{~Hz}), 7.09(\mathrm{t}, 4 \mathrm{H}, J=$ $7.6,1.3 \mathrm{~Hz}), 7.04(\mathrm{~d}, 4 \mathrm{H}), 3.77(\mathrm{t}, 4 \mathrm{H}, J=7.7 \mathrm{~Hz}), 1.65(\mathrm{~m}, 4 \mathrm{H}, J=$ 9.3, $6.2 \mathrm{~Hz}), 1.37(\mathrm{~m}, 4 \mathrm{H}), 0.87(\mathrm{t}, 6 \mathrm{H}, J=7.4 \mathrm{~Hz}) .{ }^{13} \mathrm{C} \mathrm{NMR}(125$ $\left.\mathrm{MHz}, \mathrm{CDCl}_{3}, \mathrm{ppm}\right): \delta 162.83,147.27,146.25,142.06,130.59$, 129.15, 128.10, 127.09, 124.91, 123.30, 122.95, 121.08, 109.18, 41.93, 31.66, 20.03, 13.64. Anal. calcd for $\mathrm{C}_{50} \mathrm{H}_{42} \mathrm{~N}_{4} \mathrm{O}_{2} \mathrm{~S}_{2}$ : C, 
75.54; H, 5.32; N, 7.05; O, 4.02; S, 8.07. Found: C, 75.62; H, 5.27; $\mathrm{N}, 7.10$. FTIR (KBr, $\left.\mathrm{cm}^{-1}\right): 2953,2929,2860,1644,1605,1583$, 1504, 1462, 1442, 1413, 1389, 1361, 1307, 1281, 1260, 1207, 1184, 1090, 820, 764, 743, 638.

\section{Results and discussion}

\section{Synthesis and characterization}

In this work, 2,5-dibutyl-3,6-(10-phenothiazinylphenyl)pyrrolo[3,4-c]pyrrole-1,4-dione (PDPP) was facilely synthesized via the aromatic amination reaction of $10 \mathrm{H}$-phenothiazine and 2,5dibutyl-3,6-bis(4-bromophenyl)-pyrrolo[3,4-c]pyrrole-1,4-dione (DPPC4) (shown in Scheme 1). Due to the fact that DPP pigments are limitedly dissolved in strong polar organic solvents to promote the reaction, we chose DMF as the reaction medium for the alkylation of 3,6-bis(4-bromophenyl)pyrrolo$[3,4-c]$ pyrrole-1,4 $(2 H, 5 H)$-dione with 1 -bromobutane in the presence of the organic base $t$-BuOK. The soluble DPP derivative, 2,5-dibutyl-3,6-bis(4-bromophenyl)pyrrolo[3,4-c]-pyrrole1,4-dione (DPPC4) was obtained in of $62 \%$ yield. The target compound PDPP was prepared via the aromatic amination reaction between $10 \mathrm{H}$-phenothiazine and DPPC4 under the catalysis of tri( $t$-butyl)phosphine, cesium carbonate and palladium acetate in PhMe with an acceptable yield of $21 \%$. DPPC4 and PDPP are readily soluble in common organic solvents. The pure PDPP was obtained using silica gel column chromatography and unambiguously characterized via ${ }^{1} \mathrm{H}$ and ${ }^{13} \mathrm{C}$ NMR spectra, elemental analysis and IR spectroscopy (Fig. S2†).

\section{Theoretical calculations}

The frontier molecular orbital (FMO) energy levels and optimized geometries of PDPP (Fig. 1) were calculated using density functional theory (DFT) with the Gaussian program package. The highest occupied molecular orbital (HOMO) is entirely located at the phenothiazine moieties and the lowest unoccupied molecular orbital (LUMO) is spread over the phenyl-DPP unit, which is a symmetrically convergent FMO distribution and could be used to explain the lack of solvatochromism (solvent-independent absorption and emission spectra, vide
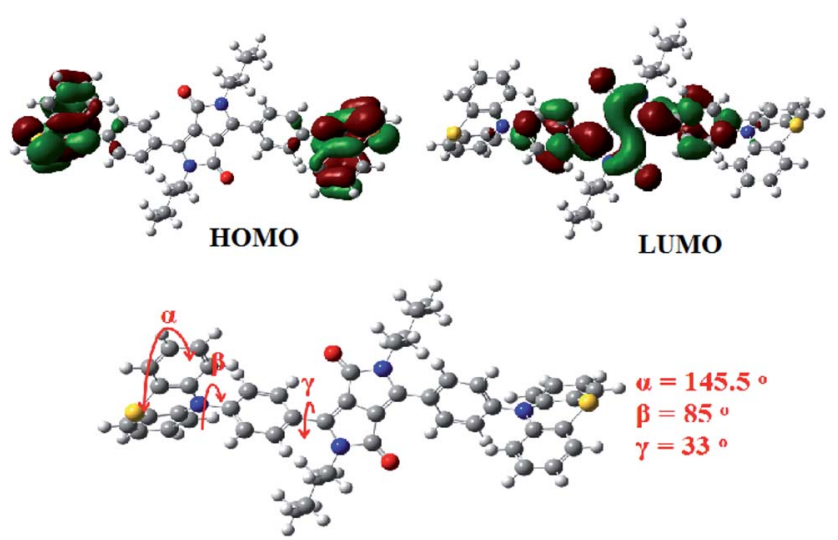

Fig. 1 Frontier molecular orbital (FMO) plots and optimized molecular geometry of PDPP. infra). The calculated HOMO and LUMO energy levels were $-5.05 \mathrm{eV}$ and $-2.65 \mathrm{eV}$, respectively. The corresponding bandgap is $2.40 \mathrm{eV}$, which is qualitatively consistent with the solution optical bandgap from the onset absorption wavelength of $571 \mathrm{~nm}$. According to DFT analysis, the phenyl conjugation bridge is twisted with respect to the DPP core and the four carbon planes of thiazine with the dihedral angles of $33^{\circ}$ and $85^{\circ}$, respectively. Moreover, the two phenyl rings of the end phenothiazine are non-coplanar (butterfly-like structure) with a dihedral angle of $145.5^{\circ}$. This distorted backbone and bent end aryl endow the molecules with active intra-molecular torsion and strong aggregate fluorescence. ${ }^{16}$

\section{Thermal and solution photophysical properties}

The thermal properties of the PDPP solid were determined using differential scanning calorimetric and thermogravimetric analysis (Fig. 2). The melting point and decomposition temperature of the PDPP solid are $265{ }^{\circ} \mathrm{C}$ and $380{ }^{\circ} \mathrm{C}$, respectively, which indicate high thermal stability. It is noted that the PDPP melt does not crystallize upon cooling, which may be ascribed to its distorted and bent backbone conformation.

The one-photon absorption and emission spectra of PDPP in four organic solvents, tetrahydrofuran (THF), chloroform $\left(\mathrm{CHCl}_{3}\right), \mathrm{PhMe}$, and DMF are shown in Fig. 3. The lowest energy absorption $\left(\lambda_{\text {abs }}\right)$ appears at about $508 \mathrm{~nm}$ which is also the strongest solution absorption band, and the molar extinction coefficients are similar within the range of 7.1-8.7 $\times 10^{4} \mathrm{M}^{-1}$ $\mathrm{cm}^{-1}$, regardless of solvent polarity.

Furthermore, the emission peaks $\left(\lambda_{\text {em }}\right)$ all appear at about $573 \mathrm{~nm}$, and the corresponding fluorescence quantum yields $(\Phi)$ in the abovementioned four solvents measured using the solution dilution method with Rhodamine B in methanol as the reference are $1.7 \%, 2.5 \%, 2.7 \%$, and $1.9 \%$, respectively. Specifically, PDPP hardly shows solvent-dependent one-photon absorption and emission properties. The lack of solvatochromism might be due to its symmetrically convergent FMO distribution (vide supra). The weak solution fluorescence

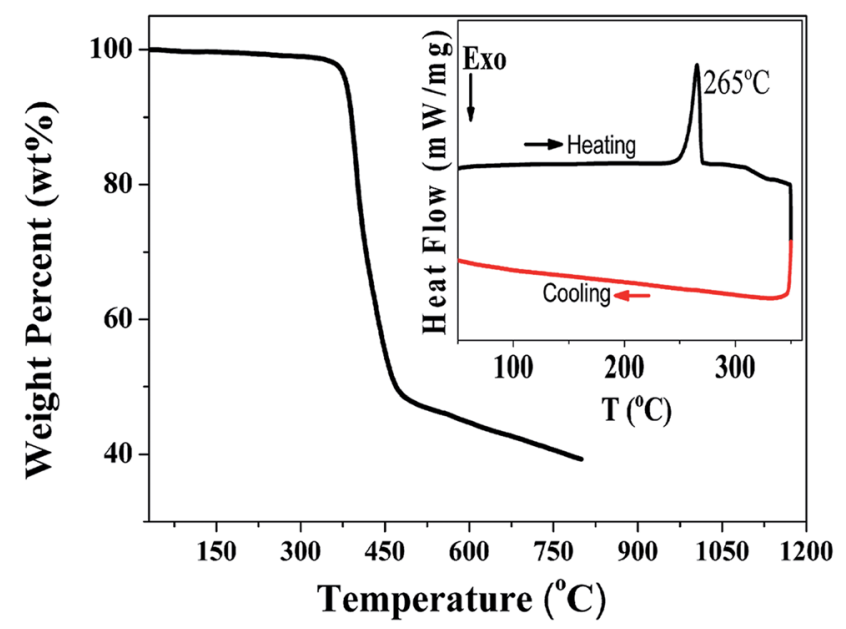

Fig. 2 Thermogravimetric and differential scanning calorimetric (inset) curves of the PDPP solid. 


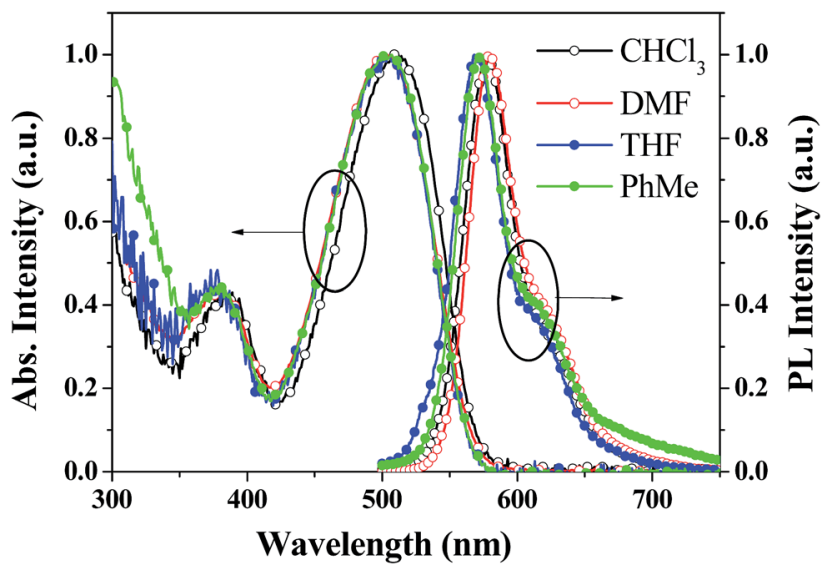

Fig. 3 Absorption and emission spectra of PDPP in different solvents at a concentration of $1.0 \times 10^{-5} \mathrm{M}$.

implies that the distorted phenyl bridges are rotatable and the non-coplanar butterfly-like phenothiazines are vibratile in molecularly dissolved fluid solutions. Intramolecular rotation and vibration motions consume the excited state energy and facilitate the non-irradiation decay. ${ }^{17}$

\section{Aggregation-enhanced emission behaviours}

Fig. 4 shows the diffuse reflectance absorption (UV) and fluorescence emission (PL) spectra of the as-prepared (pristine) PDPP solid, and the inset depicts the fluorescence imaging before and after grinding which hardly causes a colour change. The PDPP solid emits bright red fluorescence with the peak wavelength of $638 \mathrm{~nm}$ and fluorescence efficiency of $27 \%$ which was measured using a fluorescence integral sphere. The solid fluorescence efficiency is significantly higher than the solution fluorescence quantum yield, which indicates that a new DPPbased aggregation-enhanced emission (AEE) dye is developed. This phenomenon could be explained by the aggregationinduced restriction of intramolecular rotations and vibrations

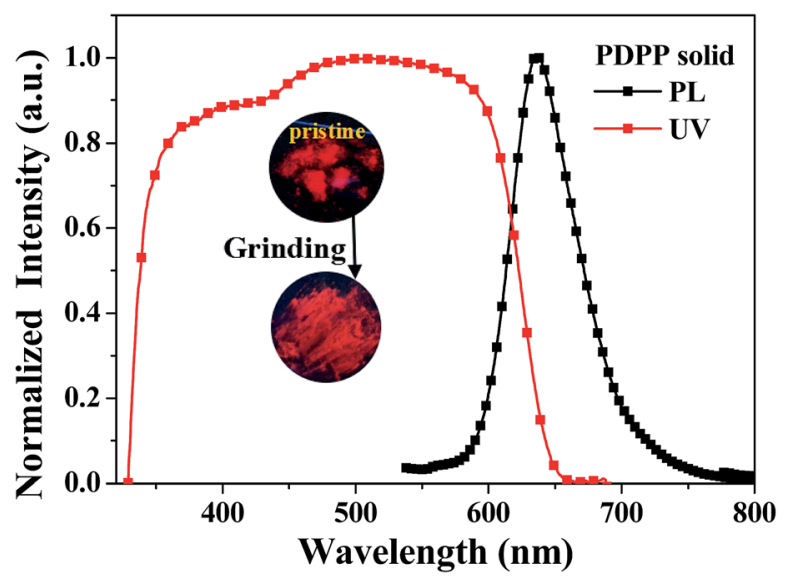

Fig. 4 Diffuse reflectance absorption (UV) and emission (PL) spectra of the pristine PDPP solid. The inset is the fluorescence image of the PDPP solid before and after grinding. which blocks the nonradiative pathway and opens the radiative channel. ${ }^{17}$ On the other hand, it is known that a distorted geometry in the monomeric form commonly limits the molecular effective conjugation length and stacking-induced planarization could extend the conjugation length. Meanwhile, the still partially distorted structure resulting from the internal steric hindrance, even after stacking, disturbs the intermolecular close packing to diminish the quenching effects. ${ }^{17 b}$ These factors render the PDPP solid a highly efficient and red-shifted emission. Since both the absorption and emission spectra of the PDPP solid are obviously red-shifted compared with that of its solution, a less twisted phenyl bridge and small phenothiazine tilt angle in its crystals are possibly suggested, even if a single crystal suitable for structure analysis has not been obtained yet. This deduction could be supported partly by the stacking-induced planarization of the phenyl bridge and phenothiazine ring in some cases. ${ }^{18}$

We also monitored the fluorescence behaviours of PDPP in THF-water mixtures with different water volume percentages $\left(f_{\mathrm{v}}\right.$, Fig. 5). Stable water dispersions of PDPP aggregates were prepared using a simple precipitation method with THF as the water-miscible solvent without any emulsifier under ultrasonic oscillations. PDPP is not soluble in water, thus the dye molecules must have aggregated in the mixtures with a high water content. Overall, the emission intensity monotonously increases with $f_{\mathrm{V}}$, except for the slight decrease at $f_{\mathrm{V}}=90 \%$. The emission intensity was about 10 times higher in the aqueous aggregates with a high water content, thus PDPP is a typical AEE

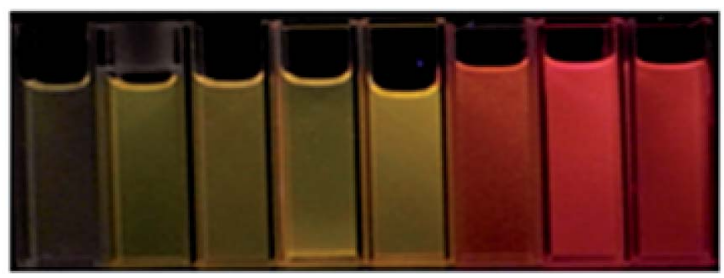

Water content

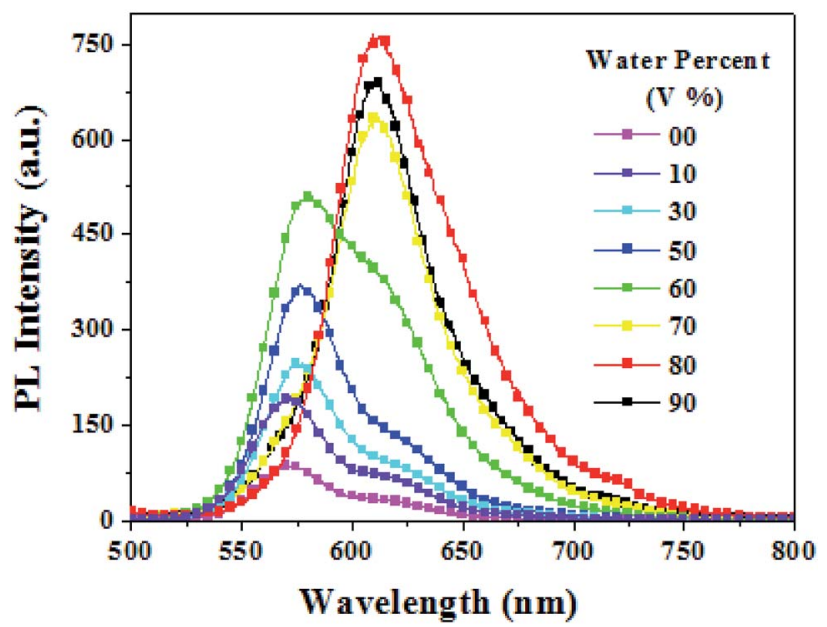

Fig. 5 Fluorescence imaging and emission spectra of TDPP in THF/ water mixtures with different water contents at a concentration of 1.0 $\times 10^{-5} \mathrm{M}$. 
dye because enhanced fluorescence emission is observed in both its solid state and aqueous aggregates. It is noticeable that the emission colours and peaks are almost unchanged (573-578 $\mathrm{nm})$ at low $f_{\mathrm{V}}(\leq 60 \%)$ but remarkably red-shifted (up to about $610 \mathrm{~nm})$ at higher $f_{\mathrm{V}}(\geq 70 \%)$. The spectral shift implies that the molecules might take a more planar conformation and/or change the packing mode from amorphous to some crystalline aggregates in aqueous solution with a high water content. The fluorescence quantum yields of the red-emitting aqueous dispersions are in the range of $0.16-0.19$ depending on the preparation conditions, such as solvent injection speed, solvent/water ratio, ultrasonic oscillation strength and overall dye concentration.

To further understand the AEE effect, we dissolved PDPP and PMMA in chloroform and spin coated the resulting solution on quartz glass to prepare a doped film ( $5 \%$ by weight), and the absorption and emission spectra of the doped film are shown in Fig. 6. Since the isolated molecules are frozen in a distorted form and the fluorescence quenching motions blocked by the rigid matrix, the absorption $\left(\lambda_{\mathrm{abs}}=506 \mathrm{~nm}\right)$ and emission $\left(\lambda_{\mathrm{em}}\right.$ $=573 \mathrm{~nm}$ ) spectra are the same as that in solution (Fig. 3). The appearance of an intense emission in the doped film (inset in Fig. 6) implies the restriction of intramolecular rotations and vibrations, and the blue-shifted emission for the doped film compared to that of the crystalline and aqueous aggregates suggest that the molecules adopted a more twisted backbone conformation in the doped film.

\section{Solution and aqueous two-photon properties}

The development of organic materials with large two-photon absorption (2PA) and excitation fluorescence (2PEF) activity has been a highly active area of research. PDPP has a favourable structure towards 2PA activity because of its donor-acceptordonor (D-A-D) motif with a strong electron-withdrawing DPP core and two strong peripheral electron-donating phenothiazines. The 2PA cross sections ( $\delta$ ) of PDPP were determined via the $2 \mathrm{PEF}$ measurement technique over a relatively wide range of

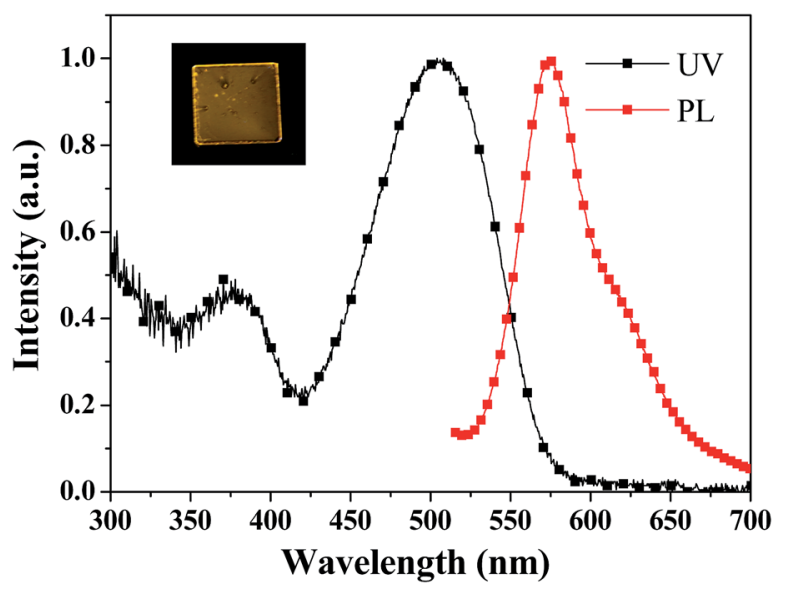

Fig. 6 Absorption (UV) and emission (PL) spectra of the doped film of PDPP in PMMA. The inset is the corresponding fluorescence image under $365 \mathrm{~nm}$ UV light. wavelengths (720-960 nm) in four different polar solvents (PhMe, THF, $\mathrm{CHCl}_{3}$, and DMF). The 2PEF technique and femtosecond laser pulses give reliable $\delta$ values by avoiding possible complications of excited state reabsorption and the thermal lens effect. The PDPP solutions, despite their low $\Phi$ values, emit determinable 2PEF. Fig. 7 shows the normalized 2PEF spectra of PDPP in different solvents under identical conditions, which display similar spectral profiles and positions, regardless of solvent polarity. Moreover, the 2PEF spectra resemble their one-photon fluorescence spectra (Fig. 3), which implies that the emissions occur from the same excited state, regardless of the mode of excitation. Since there is no onephoton absorption beyond $650 \mathrm{~nm}$ for various condensed states, the fluorescence emission excited by low-energy NIR light must be from the nonlinear absorption. It is noticed that PDPP has similar one-photon absorption and emission properties in the different solvents; however, its 2PA activity $(\delta)$ and $2 \mathrm{PEF}$ action cross sections $(\Phi \delta)$ are solvent-dependent.

The obtained two-photon excitation spectra in different solvents are shown in Fig. 8, which indicate that almost all the peak $\delta$ values appear at the excitation wavelength of $740 \mathrm{~nm}$ laser (no determinable 2PA beyond $860 \mathrm{~nm}$ ). In detail, for a given excitation wavelength, the $\delta$ values in THF are consistently the largest. The largest $\delta$ value in THF is $900 \mathrm{GM}$, which is comparable to that of most organic two-photon dyes having benzene, anthracene, and fluorene as their $\pi$-centres and $\mathrm{C}=\mathrm{C}$ bonds as the conjugation bridge. ${ }^{7}$ The calculated $\delta_{\max } / \mathrm{MW}$ is as high as 1.25 , which is valuable because molecules with a large $\delta_{\text {max }} / \mathrm{MW}$ ratio (such as $>1.0$ ) are considered to be more useful for applications that require strong $2 \mathrm{PA}$, such as optical limiting and 3-D micro-fabrication, or strong $2 \mathrm{PEF}$, such as bioimaging. ${ }^{7}$ As predicted by the quadrupolar symmetry consideration, ${ }^{7,19}$ 2PA is positioned at a shorter wavelength compared to 1PA (Fig. 9), which indicates that the two-photon-allowed state is located at a higher energy level than the one-photon-allowed state.

The aggregation effect on the 2PA activity and 2PEF was evaluated by comparing the results in aqueous dispersion (THF/ water $=1 / 9$ ) with that in THF solution at the same apparent dye

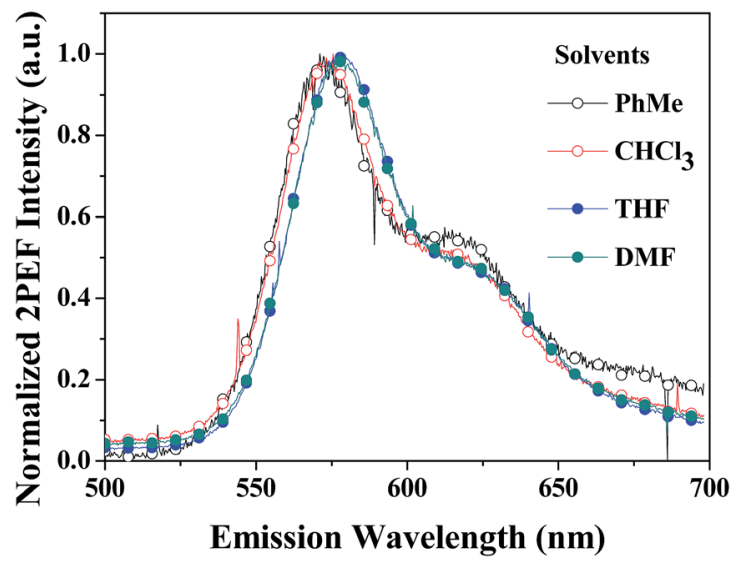

Fig. 7 Two-photon excitation fluorescence (2PEF) spectra of PDPP in different solvents at a concentration of $1.0 \times 10^{-5} \mathrm{M}$. 


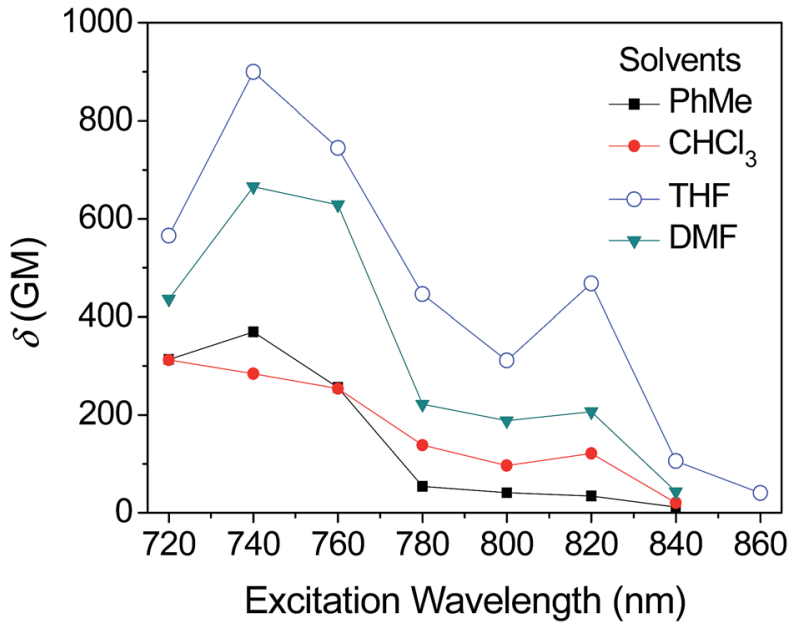

Fig. 8 Two-photon spectra of PDPP in different solvents at a concentration of $1.0 \times 10^{-5} \mathrm{M}$.

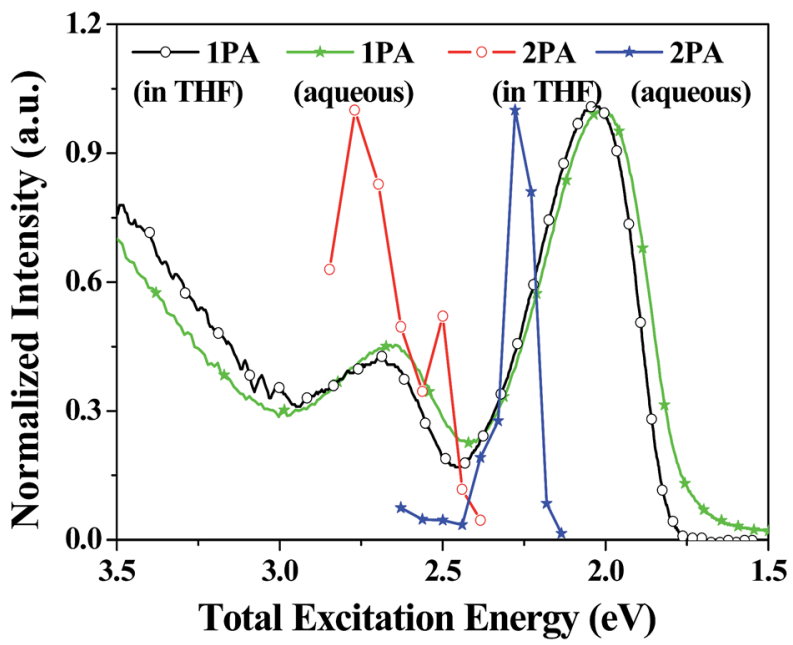

Fig. 9 Normalized one- (1PA) and two-photon absorption (2PA) spectra of PDPP in THF and THF/water (1/9). 2PA spectra are plotted against twice the laser photon energy.

concentration. Similarly, since aqueous PDPP dispersions have no one-photon absorption beyond $650 \mathrm{~nm}$, the observed fluorescence emission should also result from the nonlinear absorption excited by long-wavelength NIR light. To confirm the nature of this nonlinear absorption, we tuned the input laser powers (20-100 $\mathrm{mW}$ ) and recorded the corresponding 2PEF spectra in THF/water (1/9) mixture under a constant excitation wavelength $(880 \mathrm{~nm})$. As show in Fig. 10, aqueous PDPP is still a $2 \mathrm{PA}$-active fluorescent dye and it emits strong red $2 \mathrm{PEF}$ with spectral profiles similar to the one-photon emissions in aqueous media. Moreover, the plot of logarithmic output fluorescence intensity versus logarithmic input laser power affords a power-law dependence with the exponent of $\sim 1.9$ (the inset in Fig. 10), which is indicative of a two-photon excitation (absorption) process.

Importantly, PDPP still exhibits large $\delta$ in aqueous media, and the $\delta$ values are comparable with that in THF solution

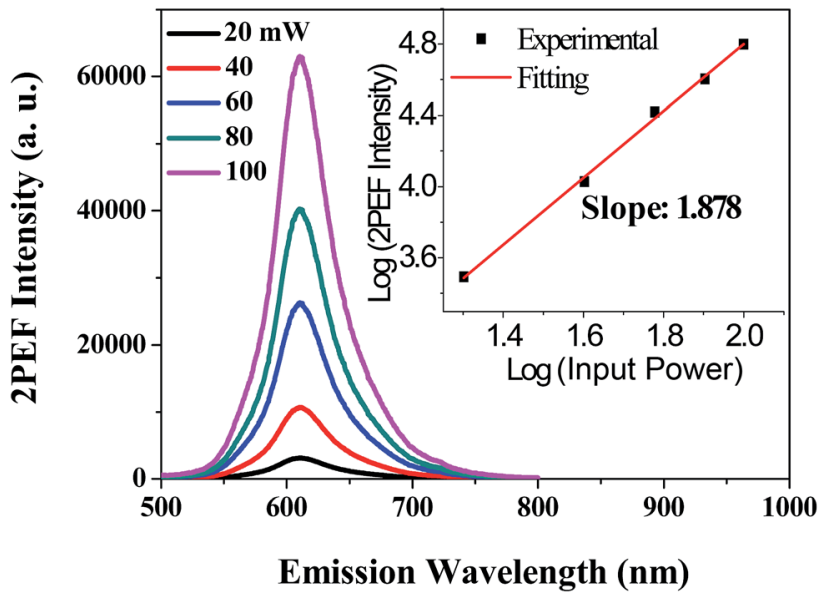

Fig. 102 2PEF spectra of PDPP in THF/water (1/9) at a concentration of $1.0 \times 10^{-5} \mathrm{M}$ excited at $880 \mathrm{~nm}$ with a laser under different input powers $(20-100 \mathrm{~mW})$. The inset shows the square dependence of output 2PEF intensity on input laser power.

(Fig. 10). The slight decrease in $\delta$ values is probably caused by the fluctuation of effective dye concentration and the aqueous dispersion preparation. It is noted that the two-photon excitation spectrum is greatly red-shifted by molecular aggregation, and the maximal $\delta$ value (790 GM) appears at $900 \mathrm{~nm}$ in aqueous media (no determinable 2PA beyond $960 \mathrm{~nm}$ and weak 2PA before $760 \mathrm{~nm}$ ) rather than $740 \mathrm{~nm}$ in THF solutions (Fig. 8). Thus the two-photon allowed states in aqueous media are closer to the dense one-photon allowed states and located at longer wavelengths (lower energy) than that in solution (Fig. 9). The greatly red-shifted two-photon band in aqueous media might be additional evidence for the aggregation- or stackinginduced molecular planarization (vide supra). More significantly, the $2 \mathrm{PEF}$ action cross sections $(\Phi \delta)$ are greatly enhanced (about 9-fold) by the molecular self-aggregation in aqueous media because of the AEE effect (Fig. 11), which is very meaningful for applications requiring strong $2 \mathrm{PEF}$ in aqueous media. Since water soluble or dispersible two-photon red dyes with

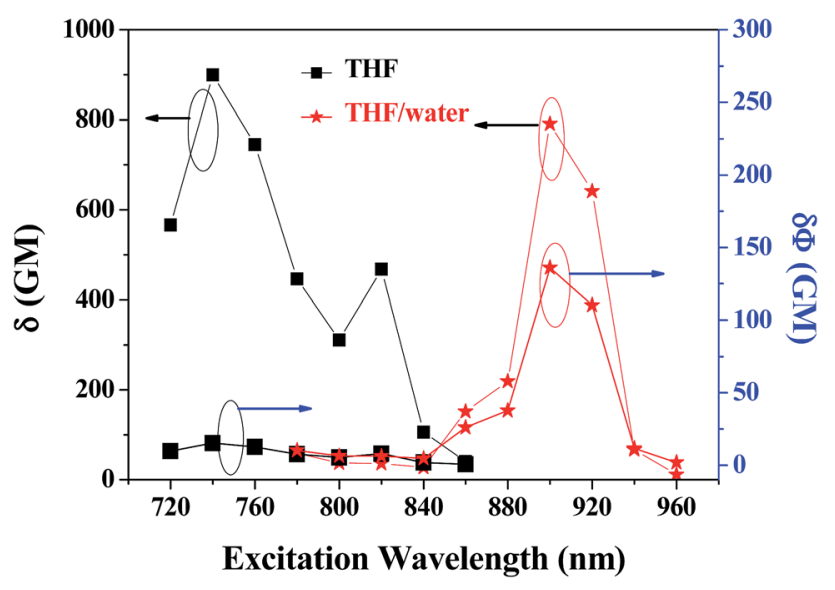

Fig. 11 Two-photon absorption (2PA) cross-section and 2PA action cross-section spectra of PDPP in THF and THF/water at a concentration of $1.0 \times 10^{-5} \mathrm{M}$. 
large $\Phi \delta$ are still scarce at present and modern laser techniques can easily vary the excitation wavelengths, PDPP should be a promising candidate for most two-photon applications including bio-imaging and phototherapy.

\section{Conclusions}

In summary, a new full-aromatic 1,4-diketo-3,6-diphenylpyrrolo[3,4-c]pyrrole derivative with phenothiazin- $N$-yl as the end donors (PDPP) has been synthesized and characterized. It is found that PDPP shows solvent-independent one-photon absorption and emission properties but solvent-dependent 2PA cross sections. PDPP emits weak orange fluorescence in solution but strong red fluorescence in aqueous media and solid state, which affords a new DPP-based AEE dye. PDPP exhibits large 2PA cross sections in both solution and aqueous media, and its aqueous self-aggregation greatly red-shifts the two-photon allowed-state. The AEE effect significantly enhances the $2 \mathrm{PEF}$ action cross section, which is very meaningful for applications requiring large $2 \mathrm{PA}$ cross sections and strong $2 \mathrm{PEF}$ such as bio-imaging and phototherapy. Overall, we have obtained a stably water-dispersible DPP-based fluorescent dye with a small molecular size and high 2PA activity, which demonstrates that the peripheral groups significantly affect the aggregation behaviours and optical properties of DPP-based derivatives.

\section{Acknowledgements}

We thank the financial support from the NSF of China (51473084, 51673105 and 51573081), the NSF of Shandong Province (ZR2014EMQ013 and ZR2016JL016), and the Natural Science Foundation of Qingdao City of China (16-5-1-89-jch). We are also grateful for China Postdoctoral Science Fund (2015M582061, 2014M560537), and Open Project of State Key Laboratory of Supramolecular Structure and Materials of Jilin University (SKLSSM201728).

\section{Notes and references}

1 (a) J. Mizuguchi and A. C. Rochat, J. Imaging Technol., 1991, 17, 123; (b) J. Mizuguchi, G. Giller and E. Baeriswyl, J. Appl. Phys., 1994, 75, 514; (c) Z. Hao and A. Iqbal, Chem. Soc. Rev., 1997, 26, 203; (d) A. Iqbal, L. Cassar, A. C. Rochat and J. Pfenninger, J. Coat. Technol., 1988, 60, 37.

2 (a) Y. Qu, J. Hua and H. Tian, Org. Lett., 2010, 12, 3320; (b) M. Kaur and D. H. Choi, Chem. Soc. Rev., 2015, 44, 58; (c) M. Grzybowski and D. T. Gryko, Adv. Opt. Mater., 2015, 3, 280.

3 (a) P. Sonar, T.-J. Hab and A. Dodabalapur, Phys. Chem. Chem. Phys., 2013, 15, 7475; (b) J. Yue, J. Liang, S. Sun, W. Zhong, L. Lan, L. Ying, W. Yang and Y. Cao, Dyes Pigm., 2015, 123, 64; (c) W. Hong, B. Sun, H. Aziz, W.-T. Park, Y.-Y. Nohd and Y. Li, Chem. Commun., 2012, 48, 8413; (d) H. Zhu, W. Huang, Y. Huang, J. Yang and W. Wang, Dyes Pigm., 2016, 127, 37; (e) C. B. Nielsen, M. Turbiez and I. McCulloch, Adv. Mater., 2013, 25, 1859.
4 (a) L. Favereau, J. Warnan, Y. Pellegrin, E. Blart, M. Boujtita, D. Jacquemin and F. Odobel, Chem. Commun., 2013, 49, 8018; (b) W. W. H. Wong, J. Subbiah, S. R. Puniredd, B. Purusho-thaman, W. Pisula, N. Kirby, K. Meullen, D. J. Jones and A. B. Holmes, J. Mater. Chem., 2012, 22, 21131; (c) P. Sonar, G.-M. Ng, T. T. Lin, A. Dodabalapur and Z.-K. Chen, J. Mater. Chem., 2010, 20, 3626; (d) W. Li, K. H. Hendriks, A. Furlan, M. M. Wienk and R. A. J. Janssen, J. Am. Chem. Soc., 2015, 137, 2231; (e) S. Qu and H. Tian, Chem. Commun., 2012, 48, 3039.

5 (a) E. Guo, P. Ren, Y. Zhang, H. Zhang and W. Yang, Chem. Commun., 2009, 45, 5859; (b) C. Yang, M. Zheng, Y. Li, B. Zhang, J. Li, L. Bu, W. Liu, M. Sun, H. Zhang, Y. Tao, S. Xue and W. Yang, J. Mater. Chem. A, 2013, 1, 5172; (c) Y. Li, M. Zheng, J. Wang, Y. Gao, B. Zhang and W. Yang, Dyes Pigm., 2014, 104, 97; (d) C. Yang, M. Zheng, Y. Li, D. Zhang, S. Xue and W. Yang, J. Polym. Sci., Part A: Polym. Chem., 2014, 52, 944; (e) M. Grzybowski, A. Jeżewski, I. Deperasińska, D. H. Friese, M. Banasiewicz, V. Hugues, B. Kozankiewicz, M. Blanchard-Desce and D. T. Gryko, Org. Biomol. Chem., 2016, 14, 2025; (f) M. Grzybowski, V. Hugues, M. Blanchard-Desce and D. T. Gryko, Chem.Eur. J., 2014, 20, 12493; (g) A. Purc, K. Sobczyk, Y. Sakagami, A. Ando, K. Kamada and D. T. Gryko, J. Mater. Chem. C, 2015, 3, 742; $(h)$ A. Nowak-Król, M. Grzybowski, J. Romiszewski, M. Drobizhev, G. Wicks, M. Chotkowski, A. Rebane, E. Górecka and D. T. Gryko, Chem. Commun., 2013, 49, 8368.

6 (a) Z.-F. Chang, L.-M. Jing, B. Chen, M. Zhang, X. Cai, J.-J. Liu, Y.-C. Ye, X. Lou, Z. Zhao, B. Liu, J.-L. Wang and B. Z. Tang, Chem. Sci., 2016, 7, 4527; (b) S. Kim, H. E. Pudavar, A. Bonoiu and P. N. Prasad, Adv. Mater., 2007, 19, 3791; (c) S. Kim, T. Y. Ohulchansky, H. E. Pudavar, R. K. Pandey and P. N. Prasad, J. Am. Chem. Soc., 2007, 129, 2669; (d) H. Ftouni, F. Bolze, H. de Rocquigny and J.-F. Nicoud, Bioconjugate Chem., 2013, 24, 942; (e) H. Ftouni, F. Bolze and J.-N. Nicoud, Dyes Pigm., 2013, 97, 77; (f) S. Mula, D. Hablot, K. K. Jagtap, E. Heyer and R. Ziessel, New J. Chem., 2013, 37, 303; (g) Y. Jin, Y. Xu, Y. Liu, L. Wang, H. Jiang, X. Li and D. Cao, Dyes Pigm., 2011, 90, 311.

7 (a) G. S. He, L. S. Tan, Q. Zheng and P. N. Prasad, Chem. Rev., 2008, 108, 1245; (b) H. M. Kim and B. R. Cho, Chem. Commun., 2009, 153.

8 (a) S. Mula, D. Hablot, K. K. Jagtap, E. Heyer and R. Ziessel, New J. Chem., 2013, 37, 303; (b) Y. Jin, Y. Xu, Y. Liu, L. Wang, H. Jiang, X. Li and D. Cao, Dyes Pigm., 2011, 90, 311; (c) H. Zhou, W. Huang, L. Ding, S. Cai, B. Li and J. Su, Tetrahedron, 2014, 70, 7050; (d) X. Y. Shen, Y. J. Wang, H. Zhang, A. Qin, J. Z. Sun and B. Z. Tang, Chem. Commun., 2014, 50, 8747; (e) Y. Gao, G. Feng, T. Jiang, C. Goh, L. Ng, B. Liu, B. Li, L. Yang, J. Hua and H. Tian, Adv. Funct. Mater., 2015, 25, 2857; (f) J. Yang, H. Tan, D. Li, T. Jiang, Y. Gao, B. Li, X. Qu and J. Hua, RSC Adv., 2016, 6, 58434.

9 (a) S. Ying, M. Chen, Z. Liu, K. Zhang, Y. Pan, S. Xue and W. Yang, J. Mater. Chem. C, 2016, 4, 8006; (b) 
Paper

View Article Online

RSC Advances

P. E. Hartnett, E. A. Margulies, C. M. Mauck, S. A. Miller, Y. Wu, Y.-L. Wu, T. J. Marks and M. R. Wasielewski, J. Phys. Chem. B, 2016, 120, 1357; (c) Y. Zhou, C. X. Guzman, L. C. Helguero-Kelley, C. Liua, S. R. Peurifoy, B. Captain and A. B. Braunschweig, J. Phys. Org. Chem., 2016, 29, 689; (d) T. Yamagata, J. Kuwabara and T. Kanbara, Tetrahedron Lett., 2010, 51, 1596.

10 J. N. Demas and G. A. Crosby, J. Phys. Chem., 1975, 75, 991. 11 (a) S. Fery-Forgues and D. Lavabre, J. Chem. Educ., 1999, 76, 1260; (b) A. T. R. Williams and S. A. Winfield, Analyst, 1983, 108, 1067.

12 M. G. Neumanna, W. G. Miranda Jr, C. C. Schmitta, F. A. Rueggeberg and I. C. Correa, J. Dent., 2005, 33, 525.

13 C. Xu and W. W. Webb, J. Opt. Soc. Am., 1996, 13, 481.

14 (a) M. Rumi, J. E. Ehrlich, A. A. Heikal, J. W. Perry, S. Barlon, Z. Hu, D. McCordMaughon, T. C. Parker, H. Rockel, S. Thayuma-navan, S. R. Marder, D. Beljonne and J.-L. Bredas, J. Am. Chem. Soc., 2000, 122, 9500; (b) W.-H. Lee, H. Lee, J.-A. Kim, J.-H. Choi, M. Cho, S.-J. Jeon and B. R. Cho, J. Am. Chem. Soc., 2001, 123, 10658.
15 (a) X. Q. Dong, M. Li, H. Q. Shi, F. Q. Cheng, J. Roose and B. Z. Tang, Tetrahedron, 2016, 72, 2213; (b) X. Y. Cai, X. L. Li, G. Z. Xie, Z. Z. He, K. Gao, K. K. Liu, D. H. Chen, Y. Cao and S. J. Su, Chem. Sci., 2016, 7, 4264.

16 J. L. Jia, L. P. Zhu, Y. Wei, Z. B. Wu, H. Xu, D. Ding, R. Chen, D. Ma and W. Huang, J. Mater. Chem. C, 2015, 3, 4890.

17 (a) Z. He, L. Zhang, J. Mei, T. Zhang, J. W. Y. Lam, Z. Shuai, Y. Q. Dong and B. Z. Tang, Chem. Mater., 2015, 27, 6601; (b) J. Mei, Y. Hong, J. W. Y. Lam, A. Qin, Y. Tang and B. Z. Tang, Adv. Mater., 2014, 26, 5429; (c) Q. Peng, Y. Yi, Z. Shuai and J. Shao, J. Am. Chem. Soc., 2007, 129, 9333; (d) S. Kim, Q. Zheng, G. S. He, D. J. Bharali, H. E. Pudavar, A. Baev and P. N. Prasad, Adv. Funct. Mater., 2006, 16, 2317.

18 (a) K. K. Zhuravlev and M. D. McCluskey, J. Chem. Phys., 2011, 114, 5465; (b) W. Liu, Y. Wang, L. Bu, J. Li, M. Sun, D. Zhang, M. Zheng, C. Yang, S. Xue and W. Yang, J. Lumin., 2013, 143, 50.

19 W. H. Lee, M. Cho, S. J. Jeon and B. R. Cho, J. Phys. Chem. A, 2000, 104, 11033.

This journal is (๑) The Royal Society of Chemistry 2017

RSC Adv., 2017, 7, 30610-30617 | 30617 